\title{
Rare case of ocular tuberculous noduloulcerative scleritis
}

\author{
Pentapati $\mathbf{M}^{1}$, Shah $\mathrm{S}^{2}$, Suresh Babu $\mathrm{G}^{3}$ \\ ${ }^{1}$ Dr Pentapati Mridula, MS Ophthalmology, Senior Resident, Department of Ophthalmology, Bangalore Medical College \\ \& Research Institute, Bangalore, India, ${ }^{2}$ Dr Suchi Shah, MS Ophthalmology, Ex-Senior Resident, Department of \\ Ophthalmology, Bangalore Medical College \& Research Institute, Bangalore, India, ${ }^{3}$ Dr Gangasagara Suresh Babu, \\ Associate Professor of Ophthalmology, Bangalore Medical College \& Research Institute, Bangalore, India
}

Address for Correspondence: Dr. Suchi Shah, MS Ophthalmology, Ex-Senior Resident, Department of Ophthalmology, Bangalore Medical College \& Research Institute, Bangalore - India, suchi.shah.87@gmail.com

\begin{abstract}
Tuberculosis is an endemic disease in developing countries like India. A scleral tuberculoma is a very rare manifestation of this disease. Ocular involvement is usually secondary to pulmonary tuberculosis or in cases of disseminated tuberculosis. A very high index of suspicion is necessary in endemic areas as the condition can be sight threatening. We hereby report a rare case of ocular tuberculosis presenting as a noduloulcerative lesion of the sclera. An otherwise healthy, 26 year old female patient, presented with redness, pain and watering in the right eye since two months. On examination an oval noduloulcerative scleral lesion was noted associated with cells and flare in the anterior chamber. Patient had a normal vision and posterior segment. After ruling out all other causes of ocular inflammation and with a positive Mantoux test, the patient was started on oral antituberculous treatment. The lesion faded and resolved over a period of two weeks. This case emphasises the necessity of ruling out tuberculosis in endemic areas where the clinical manifestations of the disease can be obscure. Early diagnosis and prompt systemic treatment gives a favourable prognosis.
\end{abstract}

Keywords: Ocular Tuberculosis, Tuberculous Scleritis, Nodular Scleritis, Noduloulcerative Scleritis.

\section{Introduction}

Tuberculosis has been declared by the World Health Organization as a global emergency since it remains the single most common cause of morbidity and mortality worldwide. It causes nearly three million deaths each year [1]. Tuberculosis is a clinical disease caused by infection with Mycobacterium tuberculosis and is characterized pathologically by the formation of granulomas [2]. Presence of a tuberculoma in the sclera is a very rare presentation of ocular tuberculosis [3]. Further, ocular tuberculosis is a common cause of infectious uveitis in endemic countries like India [4]. Nearly every ocular tissue can be affected by tuberculosis giving rise to a wide variety of clinical manifestations which include phlyctenular conjunctivitis, scleritis, uveitis, retinal vasculitis, multifocal serpiginoid choroiditis, choroid tubercles, subretinal abscess, and optic neuritis [5]. Ocular mycobacterial tuberculosis infection is most often a

Manuscript received: $7^{\text {th }}$ May 2015

Reviewed: $15^{\text {th }}$ May 2015

Author Corrected: $24^{\text {th }}$ May 2015

Accepted for Publication: $6^{\text {th }}$ June 2015 result of haematogenous spread during pulmonary or extrapulmonary tuberculosis. We hereby report a rare case of ocular tuberculosis presenting as noduloulcerative scleritis.

\section{Case Discussion}

A 26 year old female patient presented to the ophthalmology out patient department with complaints of redness, pain and watering in the right eye since two months. Patient had no history of trauma, diminished vision, photophobia, discharge or any systemic complaints.

Visual acuity in both eyes was 20/20 for distance and N6 for near.

Slit lamp examination of the right eye revealed a $3 \times 2$ $\mathrm{mm}$ obliquely oval noduloulcerative lesion of the sclera at one o'clock position close to the limbus. Deep congestion was noted around the lesion.(Fig.1) 


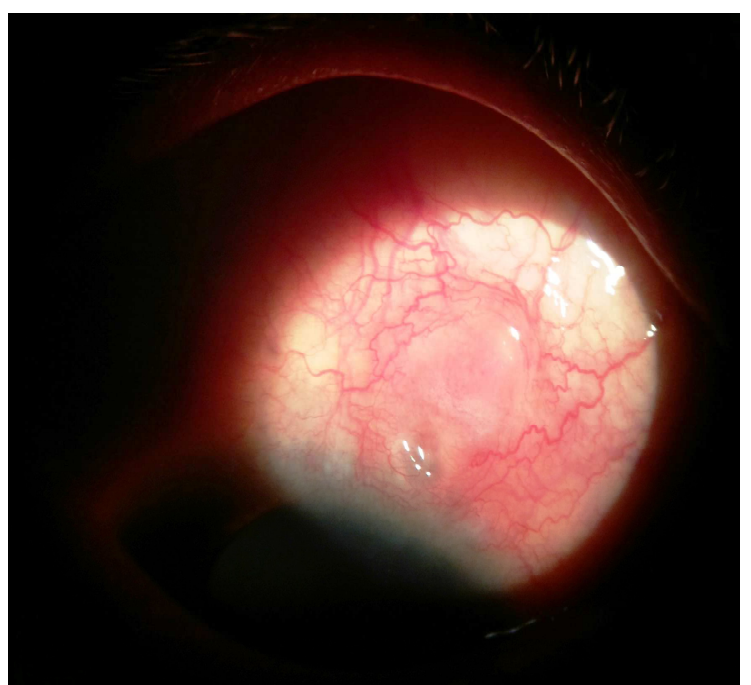

Fig 1: Slit lamp image of right eye shows an obliquely oval noduloulcerative scleral lesion with surrounding Congestion close to the limbus

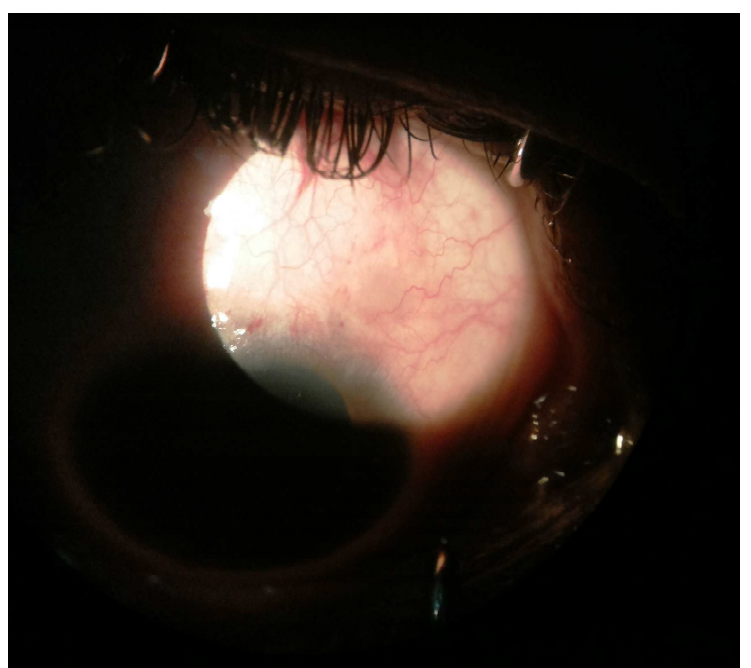

Fig 2: Slit lamp image shows a flattened scleral nodule reduced congestion

Cornea was clear, anterior chamber examination revealed 1+ cells and 1+ flare. Pupil was round, regular and reacting to light. Rest of the anterior segment examination was within normal limits. On instilling ten percent phenylephrine eye drops, congestion persisted at the nodule. Dilated fundus examination was carried out with indirect ophthalmoscope using a 20D lens and was found to be within normal limits. Anterior and posterior segment examinations of left eye were within normal limits.

Haematological investigations were done which included a complete blood count, erythrocyte sedimentation rate (ESR), fasting and post prandial blood sugars, rheumatoid factor, anti nuclear antibody (ANA) profile, VDRL, enzyme-linked immunosorbent assay (ELISA) for HIV. ESR was raised to $40 \mathrm{~mm}$ per hour with the remaining investigations being within normal limits.

Mantoux test was done by injecting $0.1 \mathrm{ml}$ (five Tuberculin Units) of purified protein derivative of Mycobacterium Tuberculosis bacilli intradermally on the ventral aspect of left forearm. Reading taken after 72 hours revealed a circular induration of $15 \mathrm{~mm}$ in its widest diameter. Roentogram of chest with a postero-anterior view was normal.

A complete physical examination was done by a physician whereby no abnormalities were detected.

Based on the above clinical findings and investigations, after ruling out other identifiable causes of ocular inflammation, with tuberculosis being endemic in our current setting, we provisionally diagnosed the patient as having right eye tuberculous noduloulcerative scleritis.

A physician reference was made in view of starting anti-tuberculous treatment. A four drug treatment regimen under category one was given as per RNTCP (Revised National Tuberculosis Control Programme) [6]. Ethambutol (1200mg), Isoniazid (600 mg), Rifampicin (450 mg) and Pyrazinamide (1500 mg) were used and patient was treated under Directly Observed Therapy Shortcourse (DOTS) strategy [7,8].

Topically, patient was put on $2 \%$ hydroxyl propyl methyl cellulose (HPMC) four times a day and 2\% homatropine eye drops twice daily. Topical steroids were avoided since it has been found that tuberculous scleritis responds to systemic antituberculous treatment rather than topical steroids [9].

Patient was reviewed every five days. At the end of first week, scleral nodule flattened, congestion reduced and anterior chamber was quiet. (Fig. 2) 
The nodule and congestion disappeared completely by the end of one month leaving a corresponding area of scleral thinning. (Fig. 3)

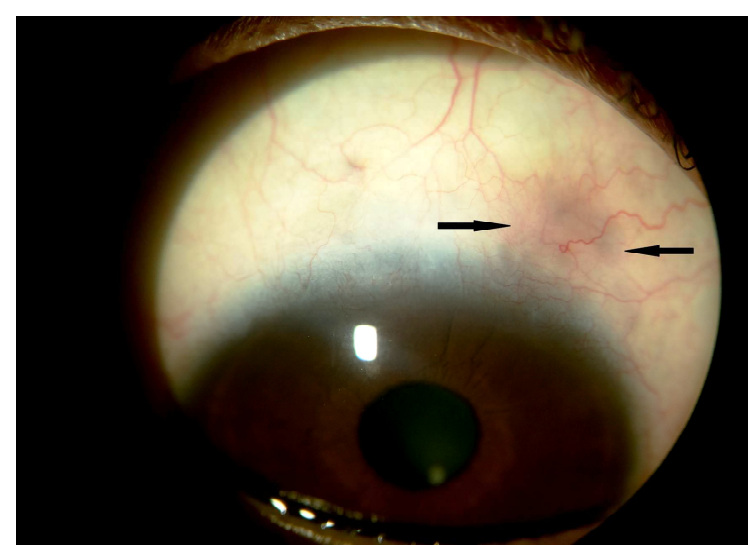

Fig 3: Slit lamp image shows complete disappearance of nodule and congestion. Arrows show the corresponding area of scleral thinning

\section{Discussion}

Keino et al. in a review of 83 patients with scleritis found that diffuse scleritis is the most common presenting form of scleritis (69\%), while nodular scleritis is less common (11\%). Of these, $55.5 \%$ of patients with nodular scleritis were found to be Mantoux positive [10]. Biswas and Badrinath examined 2,010 eyes of patients with pulmonary tuberculosis and found a $1.39 \%$ ocular involvement [11]. Sahu et al. in a case series of 55 patients with ocular tuberculosis reported scleral involvement in $14.5 \%$ cases [12]. However, the diagnosis of ocular tuberculosis is often delayed since it is difficult to differentiate its clinical manifestations from other infectious and non-infectious inflammatory conditions.

It has been shown previously that empiric antituberculosis therapy in the absence of bacteriological or histological proof of tuberculosis is beneficial in suspected cases [13]. Further, resolution of the lesion with commencing of antitubercular therapy pointed towards a causal association of the lesion with Mycobacterium tuberculosis. For the same reason histopathological analysis which is an invasive procedure was not considered in the setting of an active inflammation.

In a retrospective case series of 26 eyes with mycobacterial ocular inflammatory disease $38.5 \%$ of the cases had permanent loss of vision secondary to delay in diagnosis. Of these, two cases were enucleated after spontaneous perforation from uncontrolled necrotizing nodular scleritis. A delay in the initiation of specific antitubercular therapy can lead to recurrent or chronic inflammation and thereby long-standing visual impairment in the affected eyes [14]. Tuberculous scleritis, in absence of prompt treatment, is known to have a grave and dismal prognosis leading to extensive scleral necrosis along with uveal inflammation which can ultimately result in an unsalvageable eye [15].

\section{Conclusion}

Ocular tuberculous noduloulcerative scleritis, though rare, is still prevalent in developing countries which are endemic for the disease. In such settings, a high index of suspicion is crucial for diagnosis of the condition. Early diagnosis and prompt treatment plays a key role for this sight threatening condition, which if treated early gives a favourable prognosis.

\section{References}

1. Centers for Disease Control and Prevention: Trends in tuberculosis in United States. MMWR Morb Mortal Wkly Rep 2005;54(10):245-9.

2. Centers for Disease Control and Prevention: Case definitions for infectious conditions under public health surveillance. MMWR Morb Mortal Wkly Rep 1997;46(RR-10):1-55.

3. Biswas J, Madhavan HN, Gopal L, Badrinath SS. Intraocular tuberculosis. Clinicopathologic study of five cases. Retina 1995;15(6):461-8. 
4. Singh R, Gupta V, Gupta A. Pattern of uveitis in a referral eye clinic in north India. Indian $\mathrm{J}$ Ophthalmol 2004;52(2):121-5.

5. Gupta V, Gupta A, Rao NA. Intraocular tuberculosisan update. Surv Ophthalmol 2007;52(6):561-87.

6. Khatri GR. The Revised National Tuberculosis Control Programme: a status report on first 1,00,000 patients. Indian J Tuberc 1999;46:157-66.

7. Stop TB at the source. Geneva: World Health Organization; 1995. Report on the tuberculosis epidemic.

8. Geneva: World Health Organization; 2006. WHO: The stop TB strategy, Building on and enhancing DOTS to meet the TB related millennium development goals.

9. Sharma A, Thapa B, Lavaju P. Ocular tuberculosis: An update. Nepal J Ophthalmol 2011;3(5):52-67.

10. Keino H, Watanabe $\mathrm{T}$, Taki W, Nakashima C, Okada AA. Clinical features and visual outcomes of
Japanese patients with scleritis. $\mathrm{Br} \mathrm{J}$ Ophthalmol 2010;94(11):1459-63.

11. Biswas J, Badrinath S. Ocular morbidity in patients with active systemic tuberculosis. Int Ophthalmol 1996;19(5):293-8.

12. Sahu GN, Mishra N, Bhutia RC, Mohanty AB. Manifestations in ocular tuberculosis. Ind $\mathrm{J}$ Tub 1998;45:153-4.

13. Anglaret $\mathrm{X}$, Saba J, Perronne C, Lacassin F, Longuet $\quad$, Leport C, Vildé JL. Empiric antituberculosis treatment: benefits for earlier diagnosis and treatment of tuberculosis. Tuberc Lung Dis 1994;75(5):334-50.

14. Patel SS, Saraiya NV, Tessler HH, Goldstein DA. Mycobacterial ocular inflammation: delay in diagnosis and other factors impacting morbidity. JAMA Ophthalmol 2013;131(6):752-8.

15. Kesen MR, Edward DP, Rao NA, Sugar J, Tessler $\mathrm{HH}$, Goldstein DA. Atypical infectious nodular scleritis. Arch Ophthalmol 2009;127(8):1079-80.

\section{How to cite this article?}

Pentapati M, Shah S, Suresh Babu G. Rare case of ocular tuberculous noduloulcerative scleritis. Int J Med Res Rev 2015;3(5):528-531. doi: 10.17511/ijmrr.2015.i5.096. 